\title{
Smart Palm: An IoT Framework for Red Palm Weevil Early Detection
}

\author{
Anis Koubaa ${ }^{1, *} \mathbb{1}$, Abdulrahman Aldawood ${ }^{2}$, Bassel Saeed ${ }^{1}$, Abdullatif Hadid ${ }^{1}$, \\ Mohanned Ahmed ${ }^{1}$, Abdulrahman Saad ${ }^{1}$, Hesham Alkhouja ${ }^{1}$ and Adel Ammar ${ }^{1, *}$ \\ and Mohamed Alkanhal ${ }^{1}$ (D) \\ 1 Department of Computer Science, College of Computer \& Information Sciences, Prince Sultan University, \\ Riyadh 11586, Saudi Arabia; edbavv@gmail.com (B.S.); abdllatef64@gmail.com (A.H.); \\ mohanned.ahmed@riotu-lab.org (M.A.); abdelrahman.saad@riotu-lab.org (A.S.); hkhouja@outlook.sa (H.A.); \\ Alkanhal@psu.edu.sa (M.A.) \\ 2 Department of Plant Protection, College of Food and Agriculture Sciences, King Saud University, \\ Riyadh 11451, Saudi Arabia; aldawood@ksu.edu.sa \\ * Correspondence: akoubaa@psu.edu.sa (A.K.); aammar@psu.eu.sa (A.A.)
}

Received: 25 May 2020; Accepted: 7 July 2020; Published: 9 July 2020

check for updates

\begin{abstract}
Smart agriculture is an evolving trend in the agriculture industry, where sensors are embedded into plants to collect vital data and help in decision-making to ensure a higher quality of crops and prevent pests, disease, and other possible threats. One of the most critical pests of palms is the red palm weevil, which is an insect that causes much damage to palm trees and can devastate vast areas of palm trees. The most challenging problem is that the effect of the weevil is not visible by humans until the palm reaches an advanced infestation state. For this reason, there is a pressing need to use advanced technology for early detection and prevention of infestation propagation. In this project, we have developed an IoT-based smart palm monitoring prototype as a proof-of-concept that (1) allows monitoring palms remotely using smart agriculture sensors, (2) contribute to the early detection of red palm weevil infestation. Users can use web/mobile applications to interact with their palm farms and help them in getting early detection of possible infestations. We used an industrial-level IoT platform to interface between the sensor layer and the user layer. Moreover, we have collected data using accelerometer sensors, and we applied signal processing and statistical techniques to analyze collected data and determine a fingerprint of the infestation.
\end{abstract}

Keywords: precision agriculture; red palm weevil detection; internet-of-things; data analytics

\section{Introduction}

Smart farming is an increasingly attractive agricultural approach that leverages cutting-edge technologies to enhance productivity, provide real-time monitoring, and participate in attaining food security and sustainable production. This trend is particularly challenging in the Middle East, with regards to the increasing population and the diminishing water resources.

In Saudi Arabia, as a case study, date palms are the most cultivated trees, provide an essential food commodity, and contribute significantly to the economy. There are over 28 million date palms in the Kingdom of Saudi Arabia, which ranks third on the globe in date production (FAOSTAT, 2017). Nevertheless, date palms are threatened by an invasive pest, the red palm weevil (RPW), Rhynchophorus Ferrugineus, which was first discovered in the 1980s in the Gulf region, and has become today the most devastating pest affecting nearly 40 palm species, in more than 60 countries worldwide [1]. The number of date palms infested by RPW is exceptionally high; an estimated 
number of 80,000 infested palm trees is reported in Saudi Arabia [2], and numbers are rising rapidly. The RPW is reported to be a category-1 pest to date palms in the Gulf area [3]. The larvae of RPW are the causing agent in the infestation process, where they feed internally in the date palms trunks. This feeding behavior has a few externally visible signs, which complicates early detection. Failure in early detection of the infestation causes rotting of the internal parts of the palm trunk leading to its death [4]. It is estimated that the removal of critically infested palms costs around $\$ 8$ million yearly in the Middle East [1]. Furthermore, the RPW can complete many generations a year in the same host before its death $[5,6]$.

Consequently, a timely and precise automatic detection of such infestations would increase production quantity and quality and reduce the excessive use of insecticides that are harming the environment and public health. In this paper, we propose a comprehensive, integrated Internet-of-Things-based solution for (1) online tracking and monitoring of the vital signs of palm trees using specialized sensors, (2) detecting infestations by red palm weevils at an early stage using statistical analysis, even before it is visible to the human eye. To the best of our knowledge, this paper is the first work that provides a complete IoT system from the sensor to the end-user for the monitoring of palm trees and the early detection of the RPW.

The remaining of the paper is organized as follows. Section 2 presents a brief background and the main related works that dealt with RPW infestation detection using various sensor types and techniques. Section 3 describes the general system architecture of the smart palm framework and details its different components. Section 4 sets forth the experimental settings of the different sensors used for RPW detection and discusses the results of sensor data analysis. Finally, Section 5 draws the main conclusions of this project and suggests some future works to extend it.

\section{Related Works}

In the literature, several works proposed solutions for smart farming and agriculture based on sensors [7], drones [8], mobiles robots [9], and deep learning [10]. One of the main issues in smart farming is the early detection of red palm weevil infestation and several research works have been proposed to address this issue.

The cryptic feeding behavior of the larvae makes early detection of RPW infestation extremely hard because neither RPW larvae nor damage can be observed at this stage. Although detection of RPW infestation at early stages is not so easy, yet it is the basic step in controlling this killer pest [11-13]. The following Infestation symptoms are visible at later stages: (1) presence of galleries in the trunk of the tree, (2) oozing out of brownish viscous material with a fermented odor, (3) collection of chewed fibers between leaf bases around the trunk, (4) hearing of the feeding larvae sounds when the ear is placed close to the palm trunk, (5) presence of empty RPW cocoons and dead adults underneath the infested date palm tree, and finally (6) the falling of date palms by breaking down of the palm trunk parts [14].

So far, different methods have been tested to detect the RPW infestation in date palms in early stages. These include visual inspections and acoustic sensors [15-17], sniffer dogs [18], pheromone traps [19], transcriptome analysis [20], Laser-Induced Breakdown Spectroscopy (LIBS) [21], Near Infrared Spectroscopy (NIRS) technique [22], thermal imaging [23], TreeRadarUnit ${ }^{\mathrm{TM}}$ (TRU), and resistograph. However, none could prove desired results. Scientists are still making efforts to discover some effective, efficient and environmentally safe method for RPW early detection [24].

Visual examination of a tree is one of the regular methods that farmers perform by looking for heavy brown liquid on the palm trunk or the existence of regular or semi-regular holes on the trunk [25]. Pheromone traps are also widely used to determine the presence of RPWs in certain areas, although this method does not specify the exact infested palms [19]. For best results, the pheromone traps need to be examined regularly including a collection of the weevils, cleaning of the traps and replacement of the exhausted pheromone. The visual inspection and pheromone trapping, as well as the other traditional approaches, are the main techniques used currently for RPW detection and monitoring. 
However, many limitations are facing these techniques that include financial difficulties, trained human resources, and farmer's conception that RPW adults are attracted to their healthy farms through the presence of pheromone traps. Moreover, the poorly maintained, neglected old orchards and date palm plantations in countryside and in parks are not under the surveillance programs which sometimes act as a source of a secondary infestation.

Technological techniques are emerging in response, such as acoustic sensors [15,17]. Acoustic technology measuring the spectral and temporal patterns of sounds produced by feeding and moving larvae has the potential to enable early detection, mainly because the insect sounds often can be distinguished from agricultural or urban background noise. In [13], the authors have proposed a bioacoustic sensor for the early detection of Red Palm Weevil. It consists of a sound probe, a microphone, a processor for local computation, solar panel for energy, and a wireless interface for sending the data to a control station. Extensive experiments showed that the sensor can detect with an accuracy of $90 \%$. Similarly, [17] used an optical-fiber-distributed acoustic sensor (DAS) that can detect 12-day old RPW larvae feeding sounds, in trees that were placed in a closed room. Nevertheless, currently available acoustic systems have seen limited use because they require skilled operators.

Near-Infrared Spectroscopy (NIRS) technique [22] has been extensively used for non-destructive analysis and monitoring of biological systems. In NIRS, the specific chemical composition of an object excites molecules to absorb light in the NIR region and vibrate at unique frequencies. Insect borers cause stress to the plants interfering with transpiration stream by ingesting plant stem tissues. Similarly, when RPW infest date palm, it starts eating internal tissues of the tree and induces stress that can be detected through the NIRS technique. A preliminary study was carried out in Saudi Arabia by measuring absorbance spectra for control, wounded and RPW infested fresh date palm leaves samples through spectrophotometry. Preliminary results are promising and provide evidence that the NIRS technique has the potential for RPW detection at early stages. Infrared cameras are in use to detect temperature increase in infested palms. Currently, available literature on this aspect suggests that baseline information on temperature profiles of RPW infested date palms are available for developing a real-time sensor. Two models of IR Thermal Cameras were tested in the field in different seasons (summer and winter) to assess their efficacy in identifying the RPW damaged palms. When the thermographs of healthy and damaged palms were analyzed in some cases, the differences in the color spectrum was clear and easy to mark the damage. However, it was not easy when the surface temperature and inside temperature were not much different.

The Laser-induced breakdown spectroscopy (LIBS) technique was applied on the soil surrounding the trunk of the RPW infested date palm [21]. Results of this study showed that the presence of different elements-such as $\mathrm{Ca}, \mathrm{Mg}, \mathrm{Na}, \mathrm{C}, \mathrm{K}$, and $\mathrm{OH}$ and $\mathrm{CN}$ molecules-could be used as indicators of possible differentiating factors between infested and healthy samples. The study showed that the $\mathrm{Mg}$ and $\mathrm{Ca}$ atomic lines intensity in LIBS spectra increases rapidly with the growth of the population of the pest. These results indicate that the LIBS technique as a non-destructive method has the potential to be used as early detection for RPW infestation.

The X-Ray is a widely used technique for medical imaging, but its use in agriculture for the detection of insect pest infestation is relatively limited. Preliminary studies carried out under laboratory conditions revealed promising results. Results indicated images of the larval stages and the galleries created by RPW larvae inside the date palm trunk. Further studies are needed to improve the methodology for imaging the tree and devising a system that is compatible with date palm tree imaging under field conditions.

Near-infrared detection experimentation will hasten the use of drone-based early detection if such sensors are made based on the results of these experiments. Also, experimentation for the creation of a portable Laser-induced breakdown spectroscopy-based technology would be a handy tool in the early detection of RPW on the ground. Furthermore, in this matter, high-frequency radar and X-ray technology experiments have some promises based on preliminary experiments. 
Moreover, proteomics methods have been widely used for detecting human infections and diseases. A few plant-related proteomic studies would encourage the use of these methods for detecting RPW infestation at early stages of date palms infestations. The production of diagnostic molecular markers to be used as early detection of RPW infestation tools would work if these protein molecules would show a modulated response. This response can be used if changes in these date palms are linked with the presence of infestation by RPW. Also, experiments with proteomics strategies carry a high potential for developing future kits for early detection.

Based on the above, it can be concluded that none of such technological approaches prove desired results. Scientists are still making efforts to discover some effective, efficient, and environmentally safe method for RPW early detection. The use of a framework that collects different data from multiple sensors would help in early detection success of RPW infestations.

If an infested palm is discovered at an early stage, the efficacy of treatment is higher; which raises the significance of timely detection of RPW infestation. As long as the heart of the palm is not yet damaged and the trunk is still stable, the palm can be treated and usually recovers [26]. The RPW treatment by preventive physical, biological, or chemical means is still under research [27]. However, severely infested trees, once detected, must be destroyed [28] and completely removed as no efficient treatment process currently exists [29].

\section{Smart Palm Architecture}

In what follows, we present the general system architecture of the smart palm system and we discuss in detail its different components. A demonstration of the monitoring prototype is available on [30].

\subsection{General System Architecture}

The system is decomposed into several layers (Figure 1):

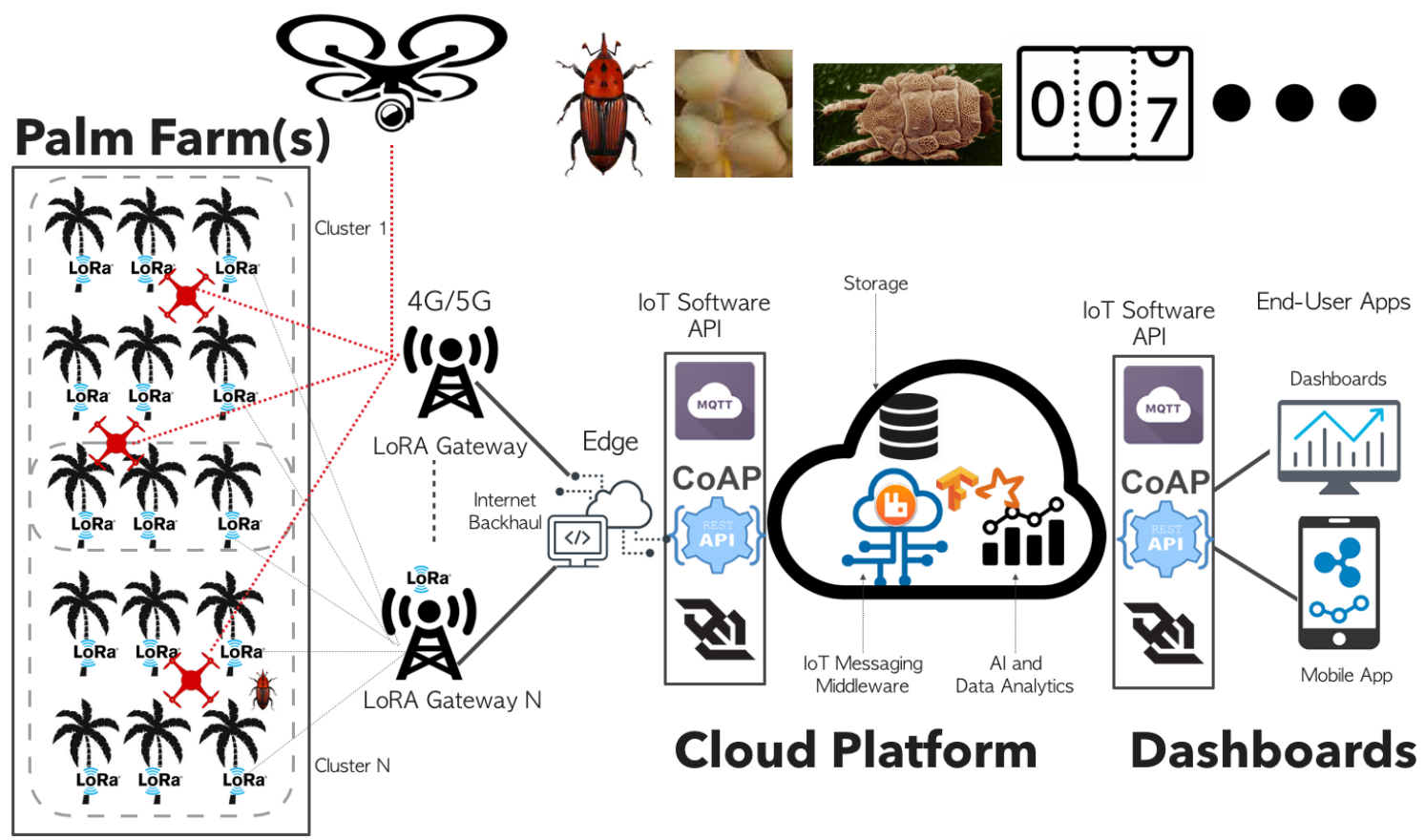

Figure 1. Smart Palm Architecture. 
- The Palm Farm Layer: This layer is the data source layer that contains all the palms distributed in multiple farms. Every palm is equipped with a sensor that captures vital information of the palm, including temperature, humidity, PH level, in addition to weevil detection sensors, namely a sound sensor (i.e., microphone) and a vibration sensor. This information is sent periodically from the sensor node to the cloud system through the gateway. The sensor nodes are equipped with a LoRA shield to allow very long-range communication with the gateway. Several studies show that LoRA achieves distances up to $20 \mathrm{~km}$, but with low data rates. In the smart palm application, the data rate is very small as data contain small number of bits and will be sent after long periods of time. As a farm can be very large, it may be decomposed into several clusters of palms, where every cluster connects to one particular LoRA gateway. In fact, a LoRA gateway can handle a limited number of connections, thus, it is necessary to have multiple clusters for farms of very large sizes. The configuration of the number of clusters per farm is a design choice.

- The LoRA Gateway Layer: this layer is the collection point of the data coming from different palms. Given that the LoRA communication range is very large, the gateway will collect data from many nodes, and then forwards them to the next Edge layer. The gateway is just a simple forwarder of messages. It does not perform any kind of processing on the data. It receives the palm vital data from its LoRA interface and forwards it to the edge through its IP Interface. Usually, both Ethernet and WiFi can be used to transmit data to the IP network.

- The Edge Layer: Data coming from palms should be transmitted to the cloud. However, as the number of palms increases, which can reach millions of palms, sending all data collected from palms directly to the cloud leads to higher storage requirements at the cloud, in addition to a higher computation complexity. This approach would lead to high management costs at the cloud in addition to possible degradation of the quality of service due to increased latency. To overcome this problem, we use an edge layer, which is an intermediate layer between the farm system and the cloud, and the edge will be responsible for a subset of data, will do local processing and send only a digest to the cloud through aggregation, thus reducing the load on the cloud and improving the QoS through reduced latency as it is closer to the devices. Edge are typically distributed in nature, and they are in a region close to where the data is originated from. This solution is more scalable and more energy efficient from the cloud perspective. An edge can be a local server or machine specific to a region or a city. For small systems, the edge layer can be ignored.

- The Cloud Layer: The cloud layer is the main central system that ensures storage and processing of collected data and the communication between the different entities of the system. The cloud layer contains a messaging middleware system (Kafka, RabbitMQ) that allows the exchange of messages between data sources and user applications. It can be accessed through different software API and communication protocols, namely MQTT, WebSockets, REST Web Service interfaces, and COAP. The cloud layer also contains big data analytics tools to perform computation and analysis of the collected data and implement advanced machine learning algorithms for the detection of the weevil infestation, and provide useful insights to the farmers.

- The End-User App Layer: The end-user applications layer contains the mobile and web applications that allow users to remotely monitor the status of the their farms in real time. A user-friendly dashboard provides the users with a comprehensive view about the state of their farms, namely the number and location of infected palms, insight on the propagation of the infestation over time, in addition to the vial data for the palms. The user can select information for a particular palm either historical or in real time. He can also display information about the whole farm and particular clusters. 


\subsection{Software Architecture}

\subsubsection{Software Component Flow Diagram}

In this section, we present the software architecture of the system. The UML flow diagram presented in Figure 2 shows the interaction between the components of the system.

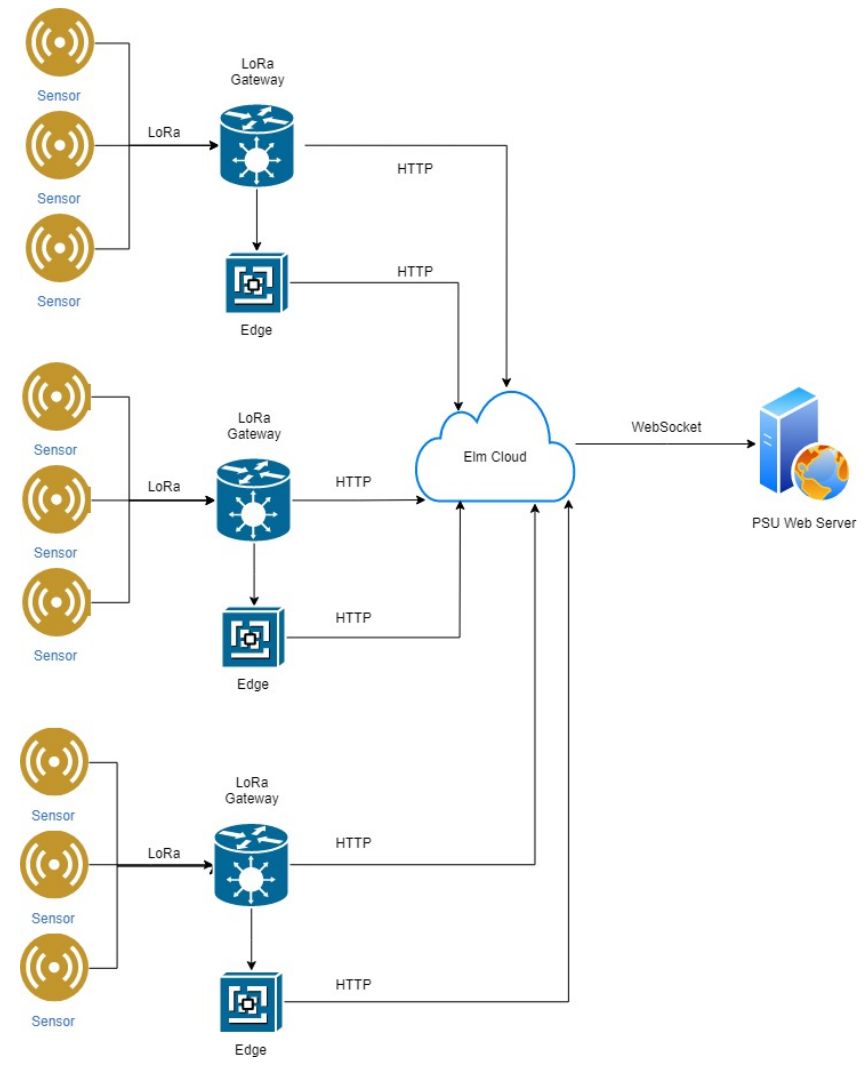

Figure 2. Flow diagram of the software system.

The process starts when the nodes receive the data from their sensors. The nodes forward the data to a gateway through their LoRA protocol interface. Then, the gateway sends the data to two destinations. The first destination is the edge where local computation is performed to get intermediate results, as explained in the general architecture section. These results are then sent to the cloud. The second destination is the cloud itself to keep the data stored for later usage and data analytics. The edge receives the data from the gateway through a WebSocket interface, while the cloud receives them through HTTP or CoAP. However, since the gateways are not constrained devices, the data is sent through an HTTP request. Finally, the cloud sends the data received from the sensors through a WebSocket to the Web Server, which in turn sends them to the client-side after doing some filtering based on the client requirements.

\subsubsection{Data Exchange Protocols}

Figure 3 presents the UML sequence diagram for the interaction between the user, the server, and the cloud. First, the Web Server must be authenticated with the cloud, which is, in our case, is the ELM cloud platform [31]. The system was designed to be easily deployed on any cloud platform using Web services and abstract software interfaces. Then, the server connects to the cloud through a WebSocket interface and listens to the data, and it sends to the cloud the list of devices from which it wants to receive their sensor readings in real time. In response, the cloud starts sending the readings of these specified devices continuously in real time to the server. Finally, the user can view these data by providing his credentials to be able to open the dashboard. 
Figure 4 represents the sequence diagram that shows the order in which the data is traveling between the nodes, edges, and the cloud. The nodes send all the data without exception to both the edge devices and the cloud. However, the edge machines perform local analysis on these data and finally send the results to the cloud, which stores them to be used later for further analysis. The edge is responsible for making local processing of data such as, for example, machine learning algorithms for RWP detection before sending it to the cloud. The data is also sent to the cloud in batches for permanent storage of the historical data for further processing, visualization, and analytics. The objective behind using edge-based processing is to reduce the load on the cloud and make the system more scalable.

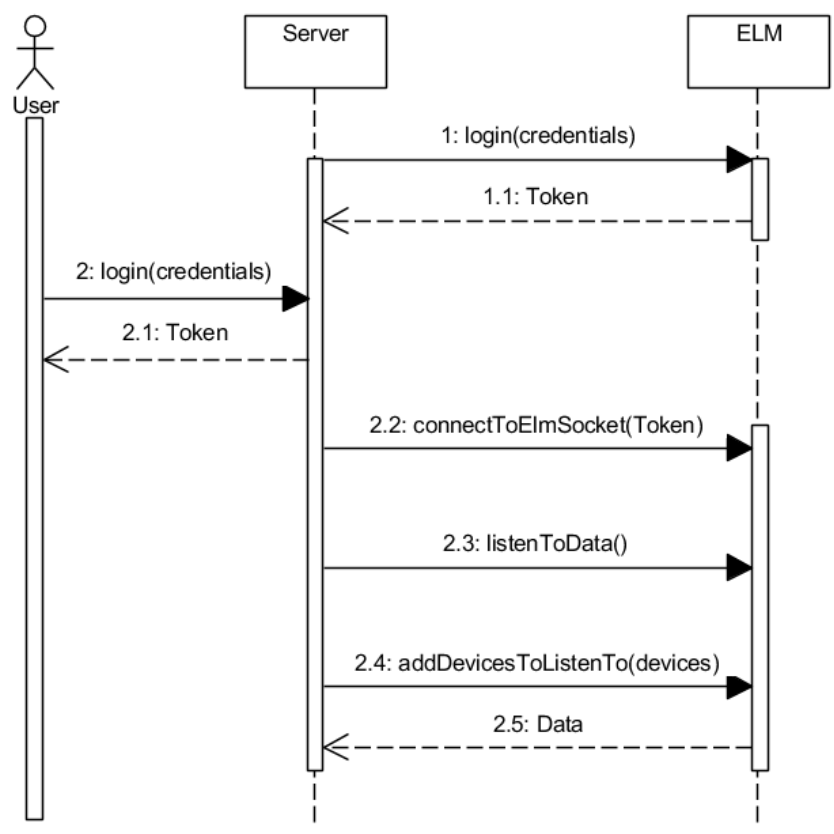

Figure 3. Sequence diagram of the Web Server, the cloud and the user.

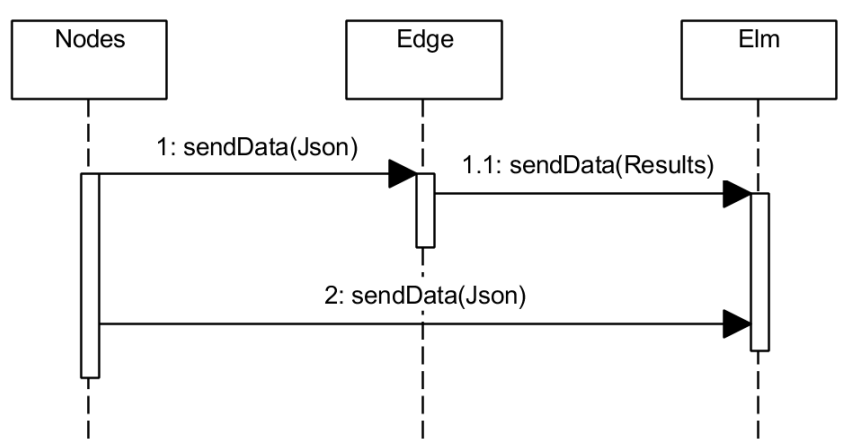

Figure 4. Sequence diagram of the nodes, edges and the cloud.

\section{Data Collection and Analysis}

\subsection{Experimental Study}

In this section, we present the experimental study that consists of using different sensors to detect the weevil insect in a palm tree. Then, we present the data analysis, discuss the findings, and present the final recommendations.

First, we present the experimental settings of the different sensors used for weevil detection, and then we explain the data collection process. We also present the different experimental scenarios, the type of sensors used, and the different parameters of the collection process. Second, we present different types of performance metrics used for weevil detection. Then, we analyze and 
compare the results, using the proposed metrics. Finally, we discuss the findings and provide some recommendations based on the results.

\subsubsection{Experimental Settings}

\section{Sensor Selection}

The selection of the appropriate sensor for weevil detection was a tedious and challenging process. In fact, the vibration and sounds generated by the weevil are found to be very small and minimal, which makes their detection through the palm tree a challenge. We have tested around 7 types of sensors ranging from vibration sensors, accelerometer sensors, and sound sensors. Among them, the accelerometer sensors were found to be the most effective. We tried different sensors with different sensitivities, and we investigated which one provides a better response to the activity of the red palm weevil. For the Arduino-based acoustic sensor (Grove Loudness Sensor based on LM2904 amplifier and a built-in microphone, and Grove Sound Sensor LM386 amplifier and an electret microphone) that we have used, we found them nonsensitive to the noise generated by the red palm weevil, so we discarded them. Moreover, it is more challenging to separate/filter the ambient noise from the real signal related to the activity of the red palm weevil. We have also tried different types of accelerometers (e.g., 3-axis Accelerometer module is based on MMA7660FC) and vibration sensors (e.g., Grove Piezo Vibration Sensor, based on PZT film sensor LDT0-028 (Manufactured by TE Connectivity, Schaffhausen, Switzerland)) and among them, the Grove 3 Axis Digital Accelerometer \pm 16 g Ultra-low Power BMA400 (Manufactured by Bosch Sensortec, Reutlingen, Germany) was providing the best signature to the activity of the red palm weevil, which is the reason of its selection for the study.

After investigation of these sensors, the experimental data collection was done using the sensor Grove 3 Axis Digital Accelerometer \pm 16 g Ultra-low Power BMA400, as shown in Figure 5 .

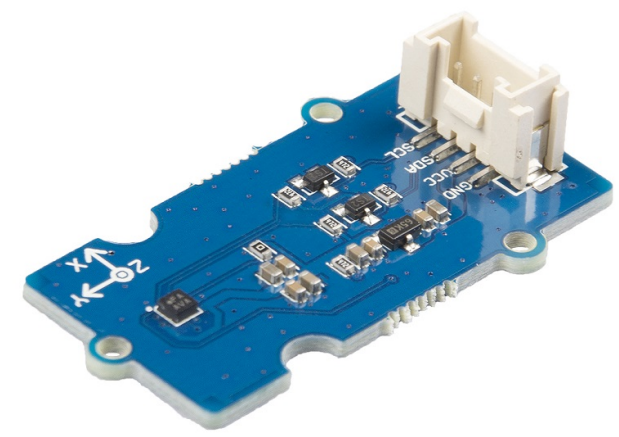

Figure 5. Grove 3 Axis Digital Accelerometer $\pm 16 \mathrm{~g}$ Ultra-low Power BMA400 Sensor.

The specification of the Accelerometer sensor is shown in Table 1. Additional information about this sensor can be found at [32].

It has to be noted that this BMA400 accelerometer sensor was selected among several other sensors, because it was found to be more sensitive than other tested sensors models, such as the Grove Vibration Sensor [33], which was not sensitive enough to the vibrations made the weevil insect, and also the microphone sensors. In fact, the vibrations and sound signals resulting from the infestation are very small and do not propagate well through the thick trunk of the palm tree. However, the Grove 3 Axis Digital Accelerometer was found to be sensitive to the vibrations of the weevil insect activities much better than all other types of sensors that we have tested. 
Table 1. Specification of the Grove 3 Axis Digital Accelerometer Sensor.

\begin{tabular}{|c|c|}
\hline Item & Value \\
\hline Operating Voltage & $3.3 \mathrm{~V} / 5 \mathrm{~V}$ \\
\hline Power Consumption & $\begin{array}{l}\text { 18uA @5 V } \\
14 u A @ 3.3 \text { V }\end{array}$ \\
\hline Operating Temperature & $-40^{\circ} \mathrm{C} \sim+85^{\circ} \mathrm{C}$ \\
\hline Acceleration Range & $\pm 2 \mathrm{~g}, \pm 4 \mathrm{~g}, \pm 8 \mathrm{~g}, \pm 16 \mathrm{~g}$ \\
\hline Sensitivity & $\begin{array}{l}1024 \mathrm{LSB} / \mathrm{g} @ \pm 2 \mathrm{~g} \\
512 \mathrm{LSB} / \mathrm{g} @ \pm 4 \mathrm{~g} \\
256 \mathrm{LSB} / \mathrm{g} @ \pm 8 \mathrm{~g} \\
128 \mathrm{LSB} / \mathrm{g} @ \pm 16 \mathrm{~g}\end{array}$ \\
\hline Interface & $\mathrm{I} 2 \mathrm{C}$ \\
\hline Size & $\mathrm{L}: 40 \mathrm{~mm} \mathrm{W:} 20 \mathrm{~mm} \mathrm{H:} 10 \mathrm{~mm}$ \\
\hline Weight & $3.2 \mathrm{~g}$ \\
\hline Package size & L: $140 \mathrm{~mm} \mathrm{W:} 90 \mathrm{~mm} \mathrm{H:} 10 \mathrm{~mm}$ \\
\hline Gross Weight & $10 \mathrm{~g}$ \\
\hline
\end{tabular}

Data Collection Process and Scenarios

The experimental study was performed on a real date palm tree brought in a container inside the premises of the Robotics and Internet-of-Things Lab.

The collection process was done at two different locations/heights that are close to the palm trunk base (around 1 meter above the ground). In fact, based on the feedback from experts, the red weevil infestation usually happens at the bottom of the tree. We have used two sensors with different orientations at each location, as shown in Figure 6.

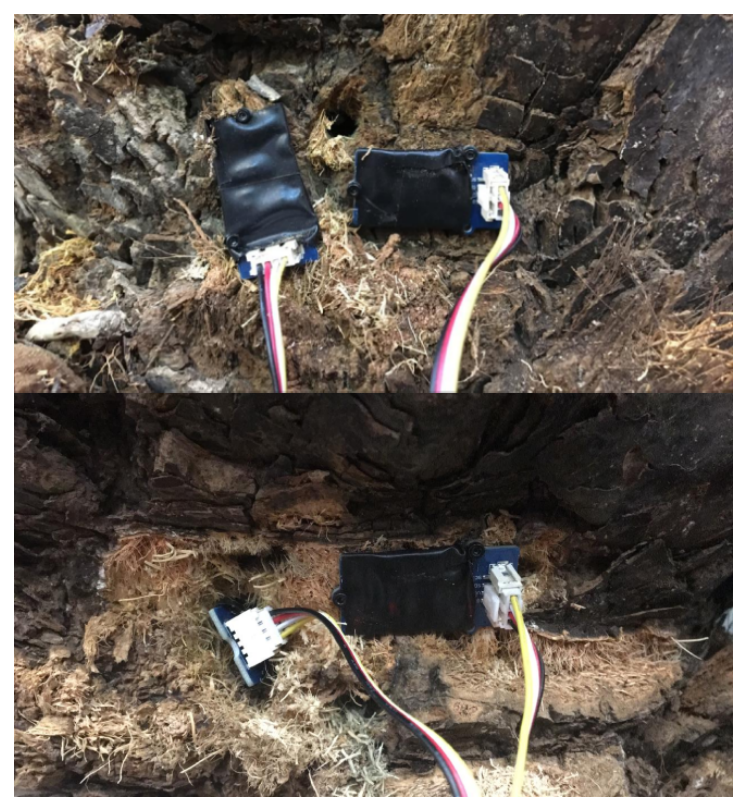

Figure 6. Sensor Placement on the Palm Tree. The bottom figure corresponds to the first scenario with one sensor inside and one sensor outside. The top figure corresponds to the second scenario with two sensors outside.

In the first scenario, the sensor node is located at the height of $35 \mathrm{~cm}$ and has two Accelerometer sensors. The first Accelerometer sensor was inserted inside the palm on the depth of $4 \mathrm{~cm}$, and the second was put on top of the trunk after removing the old stems. The reason behind trying two different 
placements is to assess the sensor response when it is located inside the palm and when it is located on top of the trunk.

In the second scenario, the sensor node was located at $20 \mathrm{~cm}$ height. In this scenario, we put both Accelerometer sensors outside the palm tree because we needed to collect more sensor data from outside the palm to check the consistency of collected data with the previous scenario. Figure 7 illustrates scenario 2 and shows a larva just inserted inside the tree.

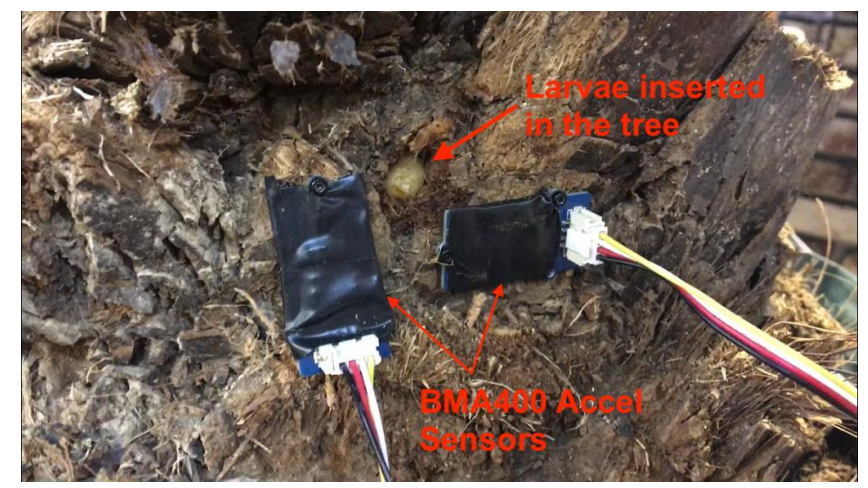

Figure 7. Position of the sensors to detect Red Palm Weevil (Outside Sensors).

We have inserted the larvae inside the tree and starts monitoring its activity. The selected red palm weevil larvae were around 1.5 to 2 months old, because the larvae are most active at this stage before becoming a pupa. We inserted four larvae at the first location and one at the second location. The data was collected and logged at both locations for six days before and after the insertion of the larvae to analyze the differences. To collect the baseline data, the data gathering process started before adding the Red Palm Larvae for $1 \mathrm{~h} 24$ min using a sensor outside the palm, and for two days using a sensor inside the palm. After inserting four larvae (three of 2 months old and one of 1.5-month old), the data was recorded inside and outside the palm for three days ( 2 days, $23 \mathrm{~h}$, and $11 \mathrm{~min}$ ). For phase two and after inserting a 1.5 months old larva, the data was recorded with two sensors outside the palm tree. After collecting and logging the data, it was cleaned by removing the outliers, which are the values above $17 \mathrm{~g}$ and the values under $6 \mathrm{~g}$. The data was collected with a delay of $10 \mathrm{~ms}$ ( $100 \mathrm{~Hz}$ frequency), and it included the acceleration on the $X, Y$, and $Z$ axes, their magnitudes, the date, the time and the number of the packets sent. Figure 8 shows a sample of larvae used in the experiments.

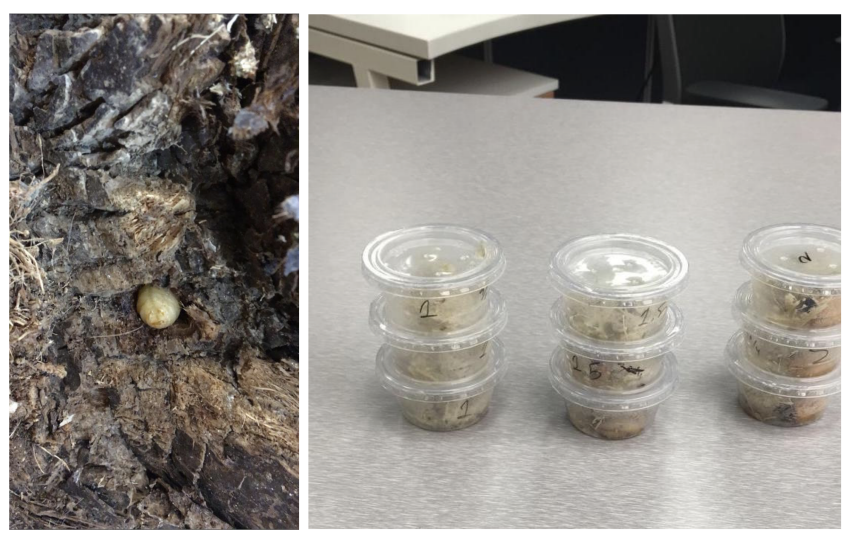

Figure 8. Larvae used in experiments.

The experimental settings used for data collection are summarized in Table 2. 
Table 2. Experimental Settings for Data Collection.

\begin{tabular}{ccccc}
\hline Location & Height $(\mathbf{c m})$ & Sensor $(\mathbf{s})$ & Positions & Number of Larvae \\
\hline 1 & 35 & BMA400 & Inside, Outside & 4 \\
\hline 2 & 20 & BMA400 & Outside & 2 \\
\hline
\end{tabular}

\subsubsection{Performance Metrics}

The objective of this experimental study is to investigate the possibility of extracting signatures of the infestation of the red palm weevil insect from the data collected in the previously described experimental scenarios. For this purpose, we have analyzed the collected data using different techniques, namely signal processing methods, and statistical methods. In what follows, we present the metrics of interest.

- Signal processing techniques: We used two approaches. The Fast Fourier Transform (FFT), which converts a time series from the time domain to the frequency domain. The objective of this technique is to investigate if the infestation of the palm would lead to different frequencies than in the case of a non-infested palm. Data were sampled at $100 \mathrm{~Hz}$. The second approach is the estimation of Power Spectral Density (PSD) using Welch's method, which is also sampled at $100 \mathrm{~Hz}$ and 2048-length for each segment. Hanning window was applied on both FFT and PSD to reduce leakage. The average value of the magnitude peaks is calculated based on the normalized threshold equal to 0.6 to evaluate both FFT and PSD plots.

- Statistical techniques: For the statistical techniques, we have considered the box-plot representation, which summarizes six statistical values, namely the maximum and minimum of all the values, the median value, the standard deviation, and the $25 \%$ and $75 \%$ percentiles. We have also considered the cumulative distribution functions and compared them against each other for different scenarios. Moreover, we have studied the Histogram representation, which provides the implicit distribution of the datasets.

\subsection{Results Analysis}

In this section, we analyze the collected data using signal processing techniques and statistical techniques. We consider the two cases where the sensors are deployed outside of the tree, and the case where the sensors are deployed inside the tree. The data values were split to hours approximately (instead of days) since RPWs cause minor changes on accelerometer readings, which make their signatures harder to observe in very large datasets. Data were collected for the first six hours. The plots were based on the combined acceleration through the $\mathrm{X}, \mathrm{Y}$, and $\mathrm{Z}$ axes all together (magnitudes). We considered the combined acceleration because all axes contribute to the detection process and it is independent of the placement of the sensor.

\subsubsection{Signal Processing Techniques}

Time series for outside and inside sensors are shown in Figures 9 and 10, where y-axis is magnitude value and $x$-axis is the index (data order in the six hours). The time domain does allow us to observe the signature easily, which is why we use signal processing and statistical techniques to analyze the collected data.

By applying the FFT technique, the data for the outside and the inside sensors are shown in Figures 11 and 12, respectively along with peaks average difference (between after, and before infestation). We can observe that when the sensor is placed inside the tree, the signature of the insect is more observable in the FFT plots as compared to outside sensor placement. In the case of the inside sensor, it is clear that most of the FFT values remain lower than 0.004 before infestation, whereas they become higher than this threshold after infestation. 

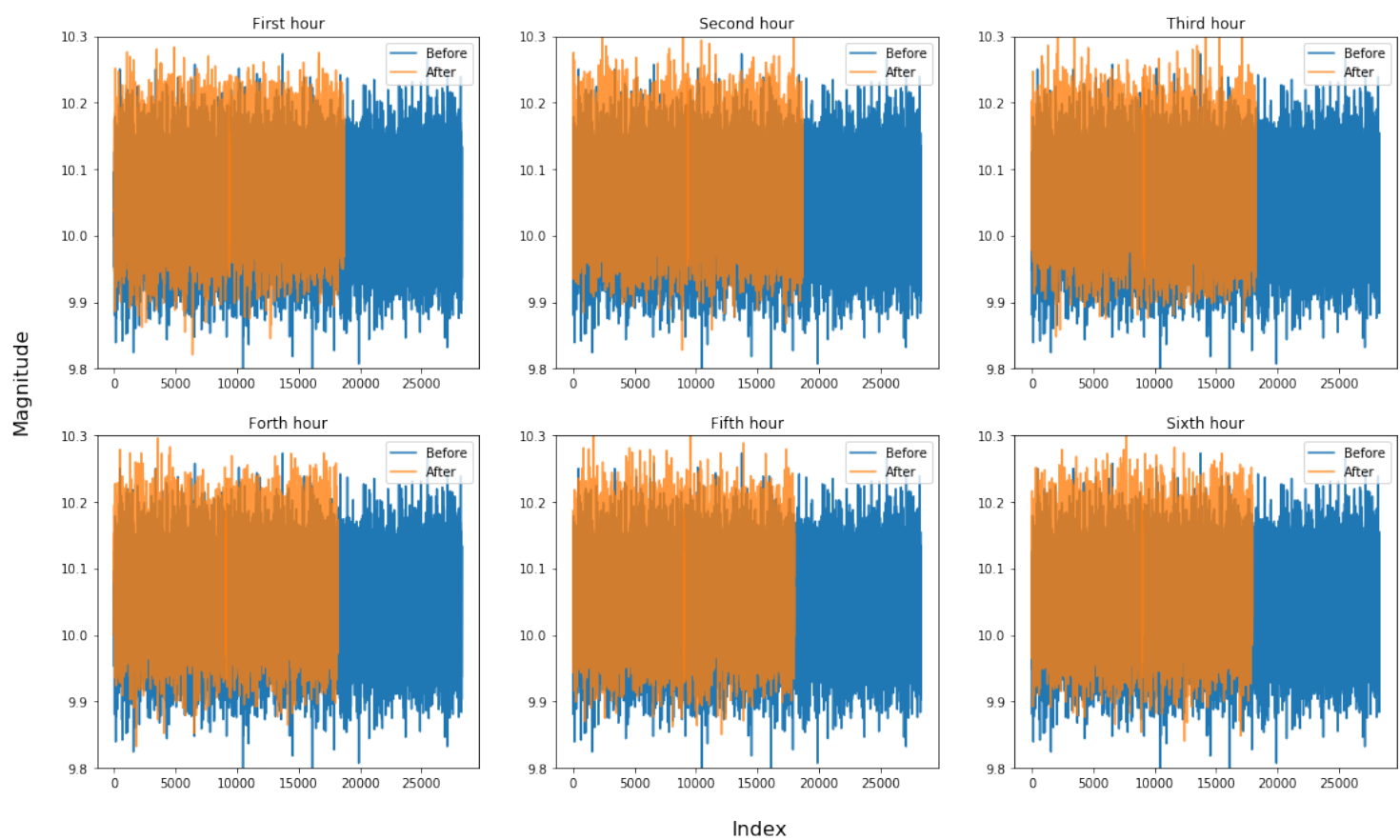

Figure 9. Time domain plot for data collected from outside sensor before and after inserting Red Palm Weevils through hours.
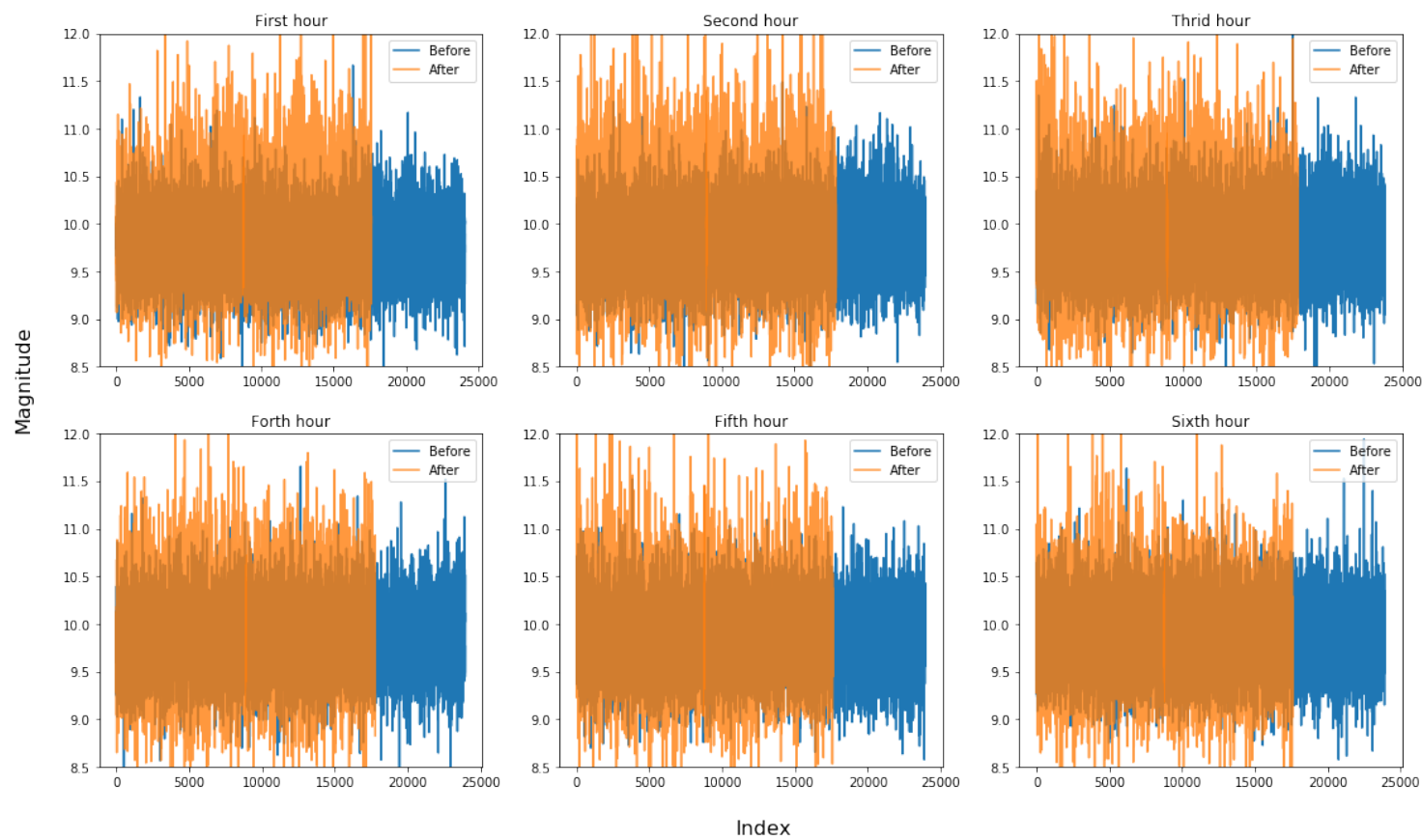

Figure 10. Time domain plot for data collected from inside sensor before and after inserting Red Palm Weevils through hours.

By applying the PSD technique, Figures 13 and 14 show the data for outside, and inside sensors, respectively, through hours along with peaks average difference (between after, and before infestation) (PAD) for the whole data values. The first 10 frequencies $(0 \mathrm{~Hz}-10 \mathrm{~Hz})$ were plotted since RPWs movements are difficult to detect at high frequencies (more than $10 \mathrm{~Hz}$ ). First, for the outside sensor figure, we can find that PSD has very small values as compared to those of the inside sensor data. Also, the outside sensor mean peaks differences fluctuate for before and after infestation. However, 
the PSD of the inside sensor placement shows a clear difference in the signal between the case before infestation and the case after infestation.
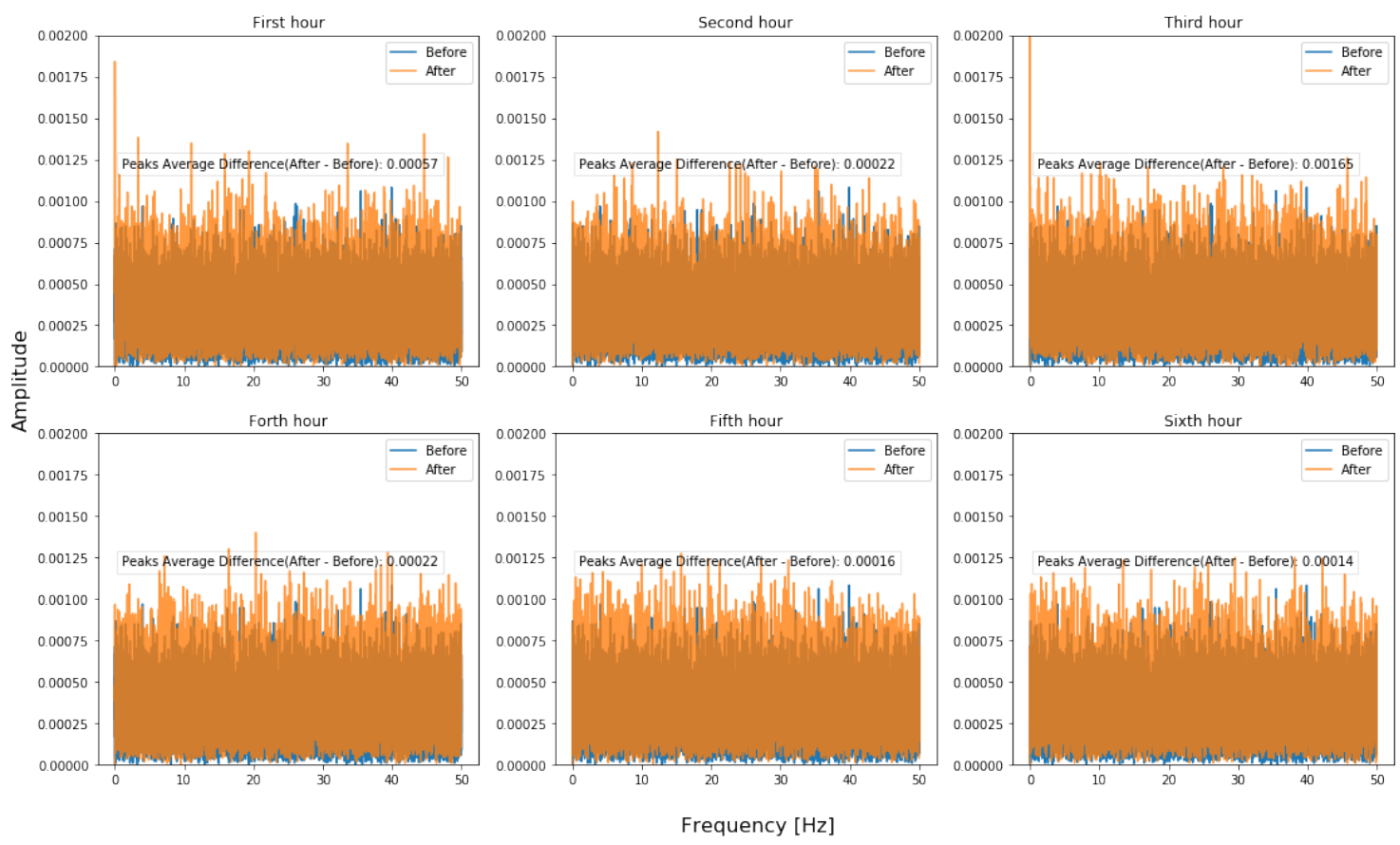

Figure 11. FFT Frequency domain plot for data collected from outside sensor before and after inserting Red Palm Weevils through hours.
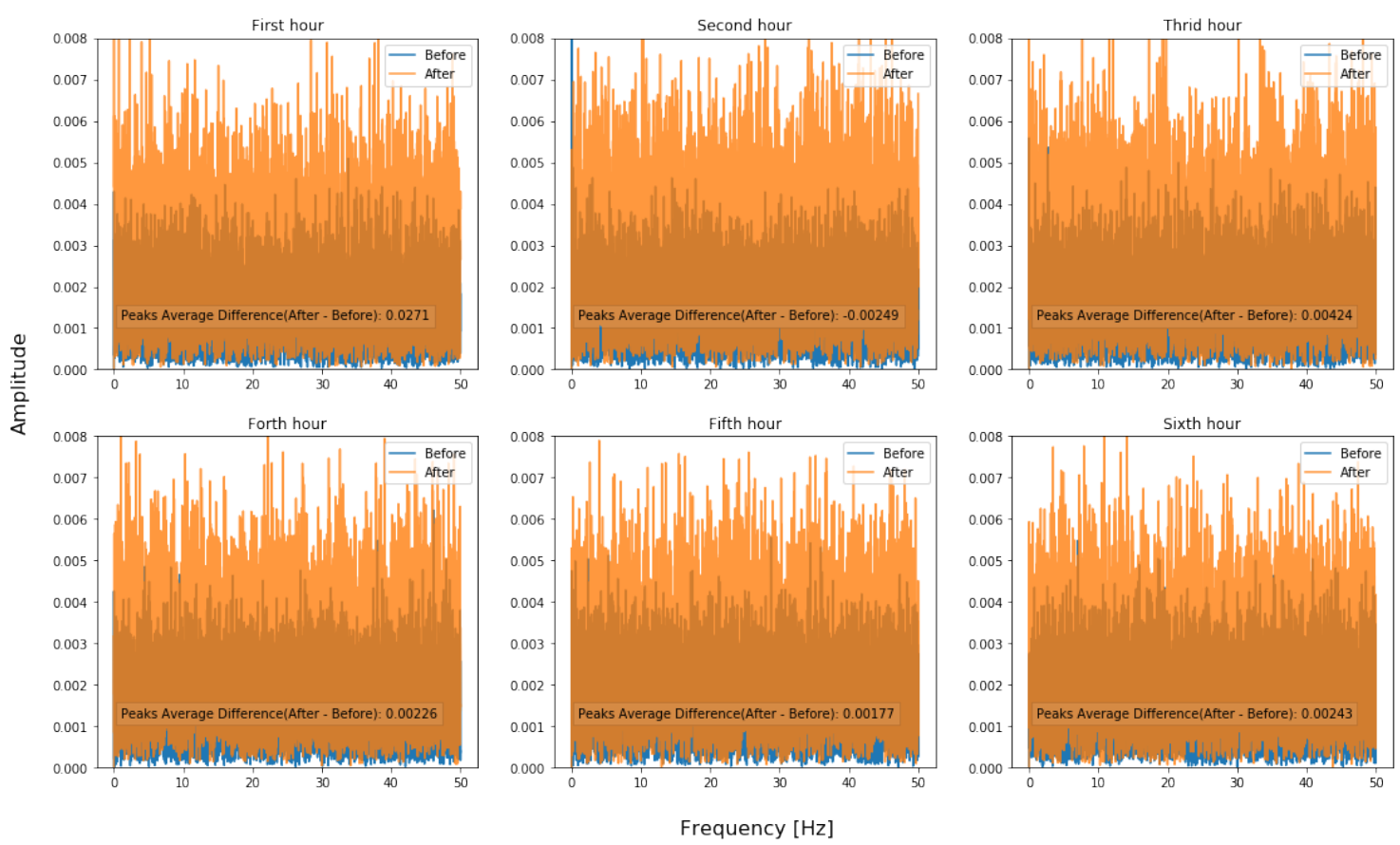

Figure 12. FFT Frequency domain plot for data collected from inside sensor before and after inserting Red Palm Weevils through hours. 

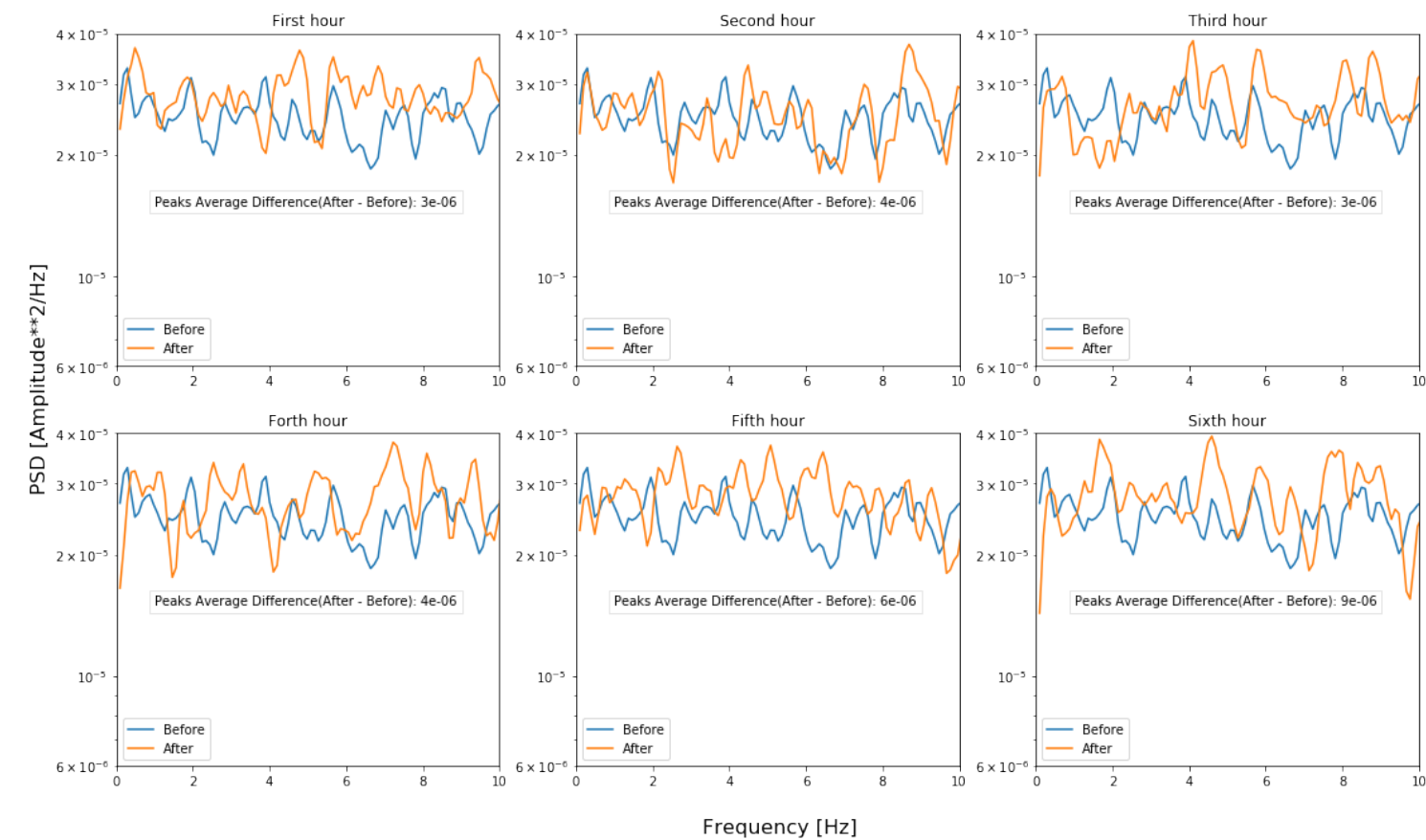

Figure 13. PSD Frequency domain plot for data collected from outside sensor before and after inserting Red Palm Weevils through hours.

We can conclude from these two observations that outside sensor placement is more prone to external environment noise as compared to the inside sensor placement; Therefore, the inside sensor placement allows us to find RPWs signature more clearly. Also, In the inside sensor placement, we can find that PSD values for data collected after infestation are much larger than data collected before infestation, and the RPW signature can be seen easily in Figure 14.
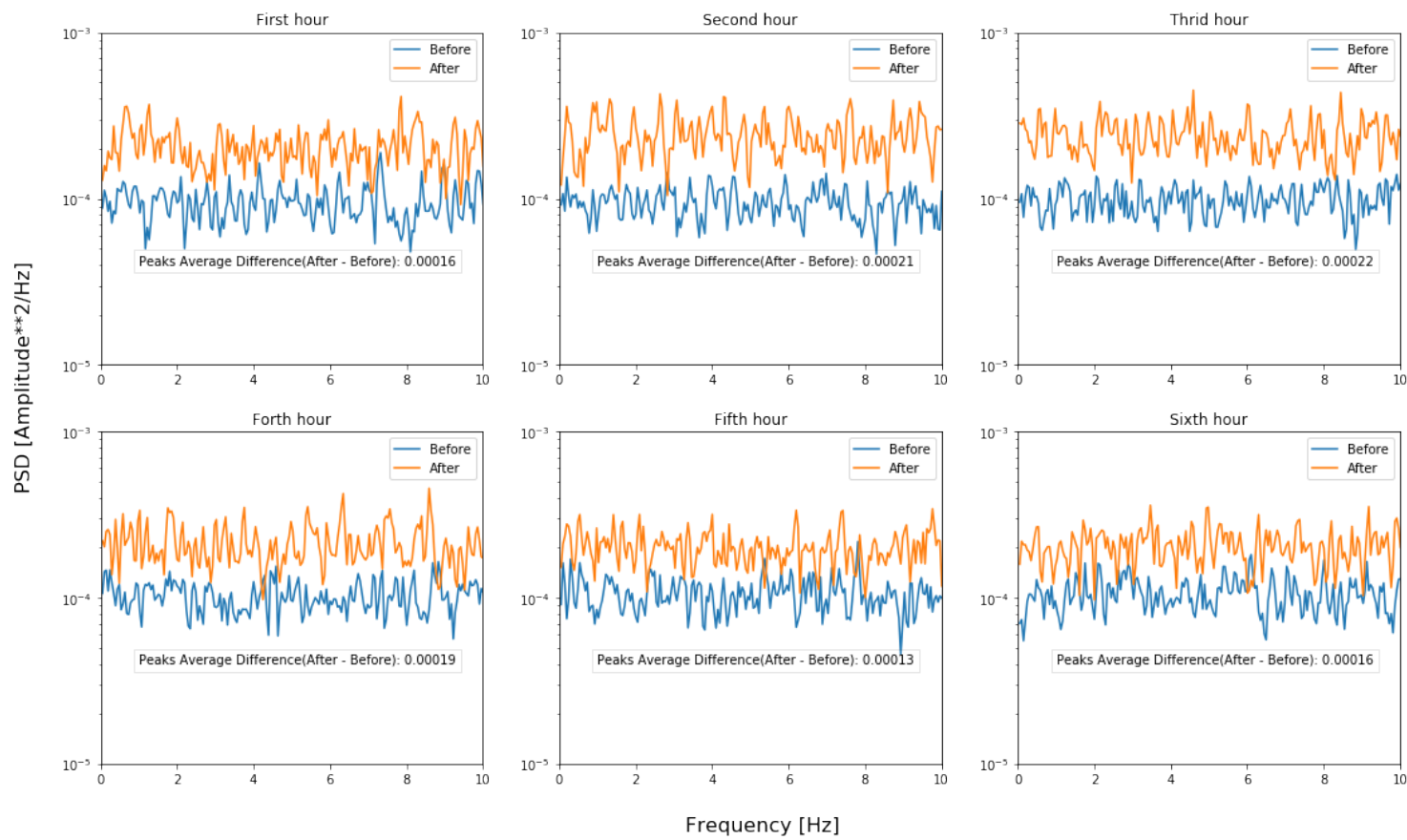

Figure 14. PSD Frequency domain plot for data collected from inside sensor before and after inserting Red Palm Weevils through hours. 


\subsubsection{Statistical Techniques}

In this section, we present the results of the statistical analysis of the collected data. We first start by analyzing the statistical properties through box plots, then by comparing the cumulative distribution functions of the collected data before and after the insertion of red palm weevil. Table 3 summarizes the central tendency and the shape of distribution for all datasets.

Table 3. Measures of Central Tendency.

\begin{tabular}{lcccccccccc}
\hline \multicolumn{1}{c}{ Data-Set } & $\begin{array}{c}\text { Sample } \\
\text { Size }\end{array}$ & Mean & $\begin{array}{c}\text { Standard } \\
\text { Deviation }\end{array}$ & Median & Minimum & $\begin{array}{c}\text { 25th } \\
\text { Percentile }\end{array}$ & $\begin{array}{c}\text { 50th } \\
\text { Percentile }\end{array}$ & $\begin{array}{c}\text { 75th } \\
\text { Percentile }\end{array}$ & $\begin{array}{c}\text { Maximum } \\
\text { (in Minutes) }\end{array}$ \\
\hline $\begin{array}{l}\text { Outside sensor } \\
\text { before insertion }\end{array}$ & 28,299 & 10.04 & 0.06 & 10.04 & 9.77 & 10.00 & 10.04 & 10.08 & 10.27 & 60 \\
\hline $\begin{array}{l}\text { Outside sensor } \\
\text { after insertion }\end{array}$ & 18,712 & 10.08 & 0.06 & 10.08 & 9.82 & 10.04 & 10.08 & 10.12 & 10.28 & 60 \\
\hline $\begin{array}{l}\text { Inside sensor } \\
\text { before insertion }\end{array}$ & 24,077 & 9.74 & 0.25 & 9.73 & 8.29 & 9.58 & 9.73 & 9.89 & 11.67 \\
\hline $\begin{array}{l}\text { Inside sensor } \\
\text { after insertion }\end{array}$ & 17,614 & 9.94 & 0.37 & 9.93 & 8.20 & 9.71 & 9.93 & 10.15 & 12.64 \\
\hline
\end{tabular}

\section{Statistical Measures}

We collected data before and after infestation using outside and inside sensors. Figures 15 and 16 present the box plots corresponding to the collected data for outside and inside sensors for one hour respectively.

We can observe that for any sensor placement, the mean and the variance of the infestation use case is larger than the case of no infestation. This is due to a more signal variation of the time series due to the acceleration induced by the motion of the insect. In the case before infestation, both the mean and the median are equal at 10.04, which indicates that the distribution is symmetric. However, in the case after infestation, we can notice how the outliers have more variety in their values. Moreover, they are much similar in case of equality between the median and the mean, with a 0.04 increase, to become 10.08 .

On the other hand, the data collected from the inside sensor (see Figure 16) has noticeable results. The subtraction between the maximum value (Third Quartile value $+1.5^{*} \mathrm{IQR}$ ) and the minimum value (First Quartile value-1.5*IQR) for the case before the infestation is 1.2169 , but for the case after the infestation has increased to 1.7720. After all, relying on the difference between maximum and minimum seems like a promising conceivable result.

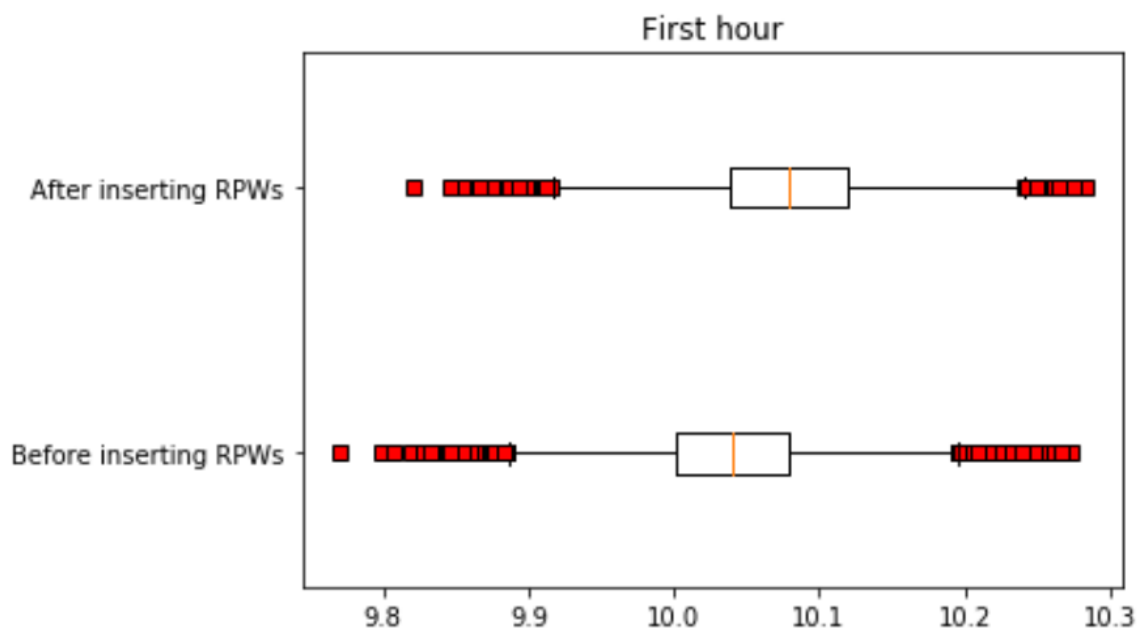

Figure 15. Box-plot graph for the outside sensor, before and after infestation for the first hour. 


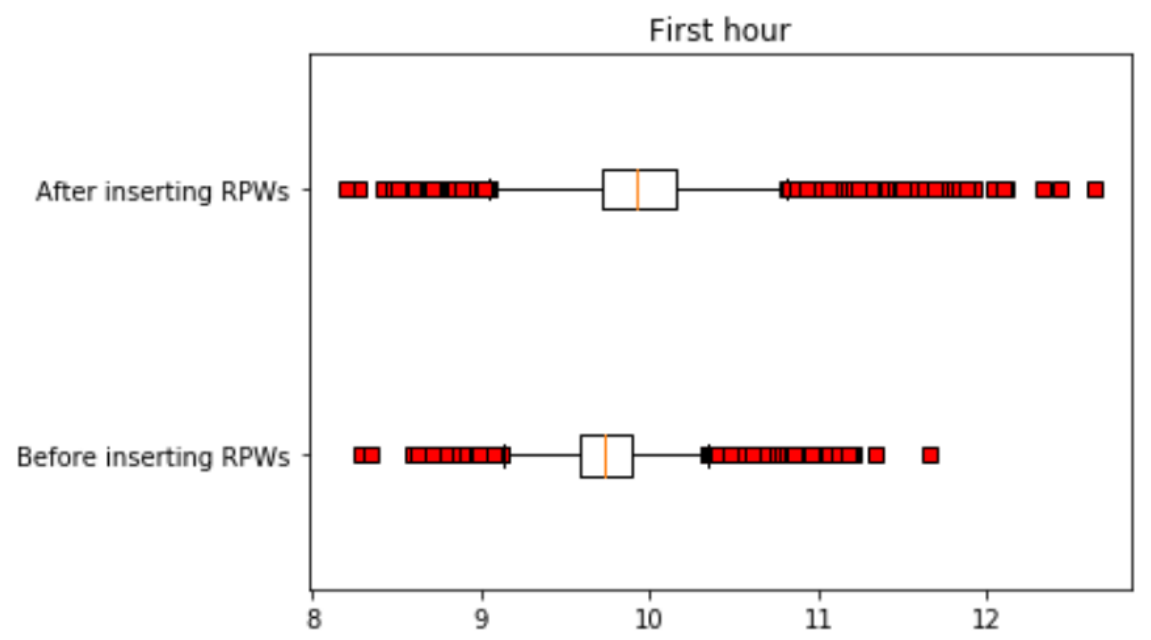

Figure 16. Box-plot graph for the inside sensor, before and after infestation for the first hour.

\section{Probability Distributions}

Figures 17 and 18 demonstrate the Histogram graphs for inside sensor and outside sensor for six consecutive hours. We experimented with the datasets using a different number of bins. We found out that 50 bins are more suitable to use.

It is clear that the distribution of data follows a Gaussian distribution for both the inside and the outside sensor placements. However, we can observe that after infestation, the bell-shape of the normal distribution becomes more spread as compared to before the infestation case. This is reasonable as data has more variation in case of infestation due to the insect motion, and thus the variance is more significant. This is even confirmed in the results of Table 3. Also, we can observe that the peak values are shifted to the right in the case of infestation as the mean is larger.

The results are consistent for all the observation windows in the six plots, where each plot represents one hour of the time window, as mentioned.
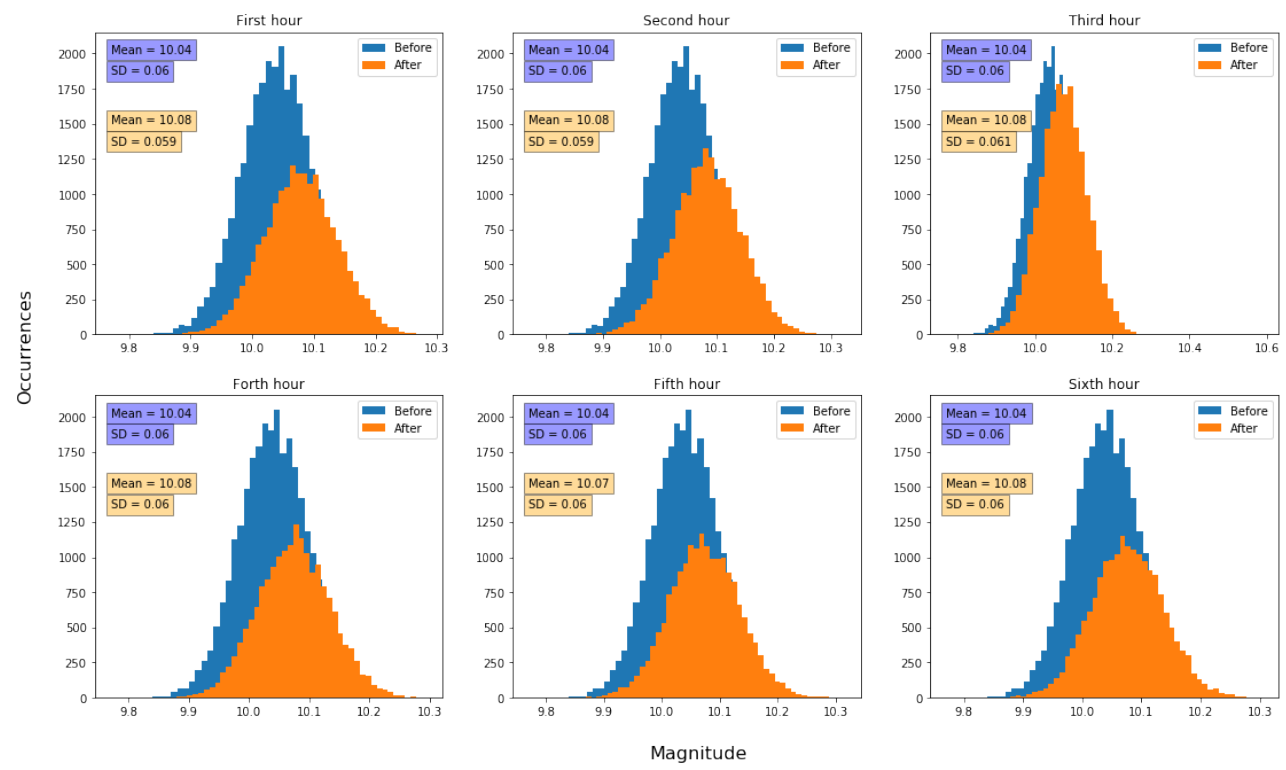

Figure 17. Histogram representation for the outside sensor, before and after inserting the RPWs for the first six hours. 

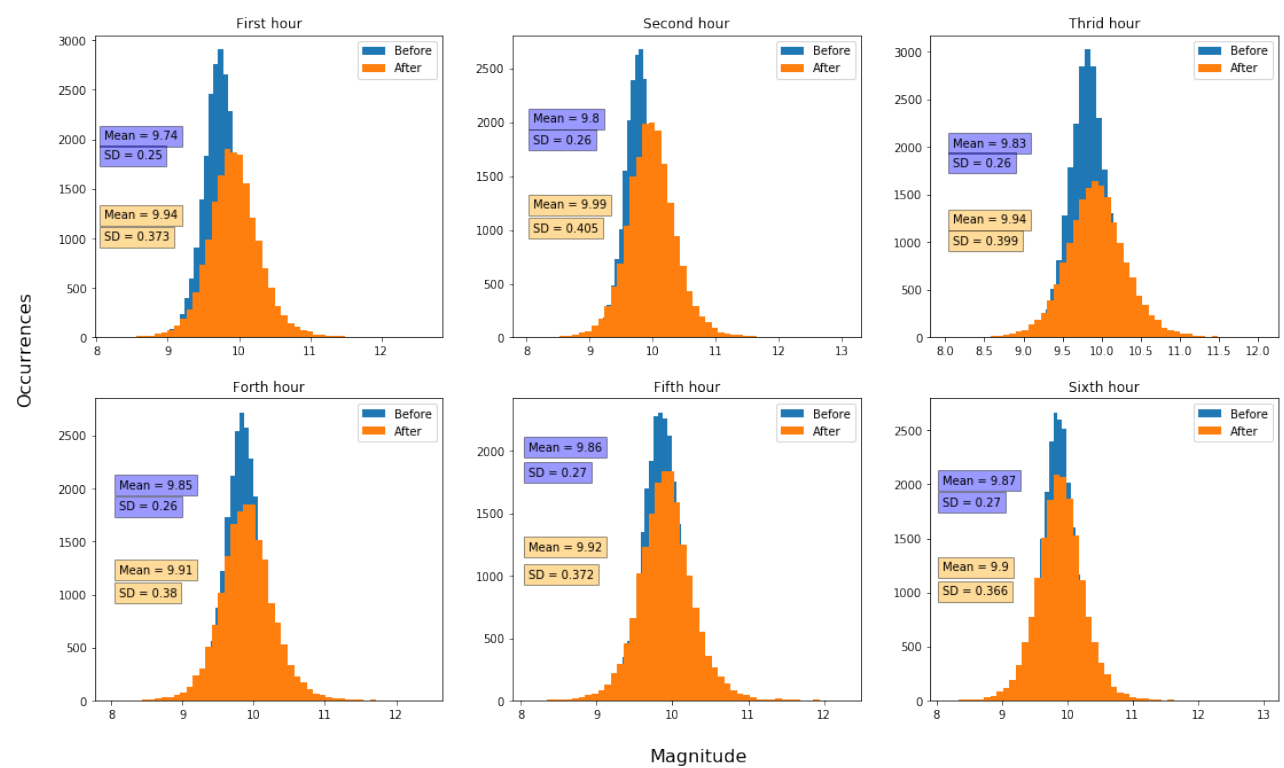

Figure 18. Histogram representation for the inside sensor, before and after inserting the RPWs for the first six hours.

\section{Cumulative Distribution Functions}

Figures 19 and 20 present the Cumulative Distribution Function (CDF) for both outside and inside sensors only for the first hour. The results confirm those of the probability distribution since the CDF before infestation and after the infestation is different. The after-infestation CDFs are lower than the before infestation CDF. This is because the data has more variance after infestation.

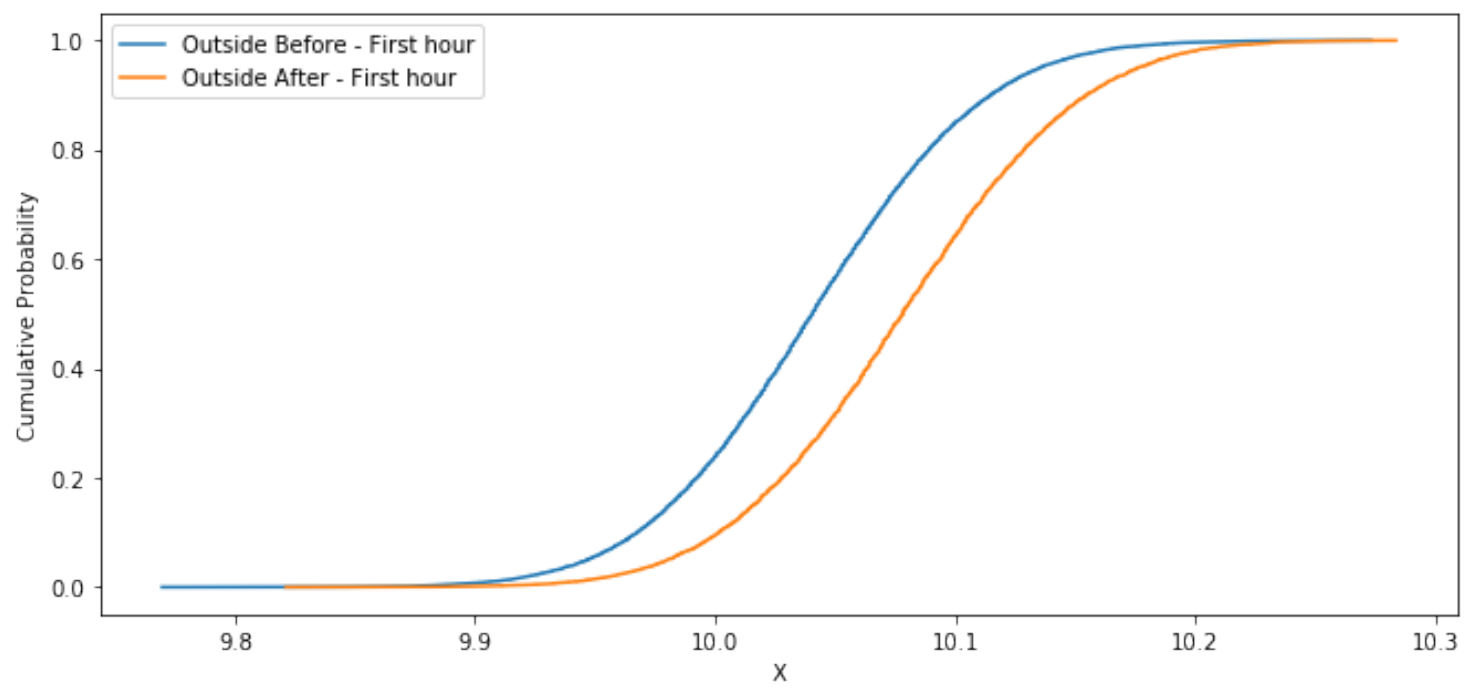

Figure 19. Cumulative Distribution Function for the outside sensor, before and after inserting the RPWs for the first hour. 


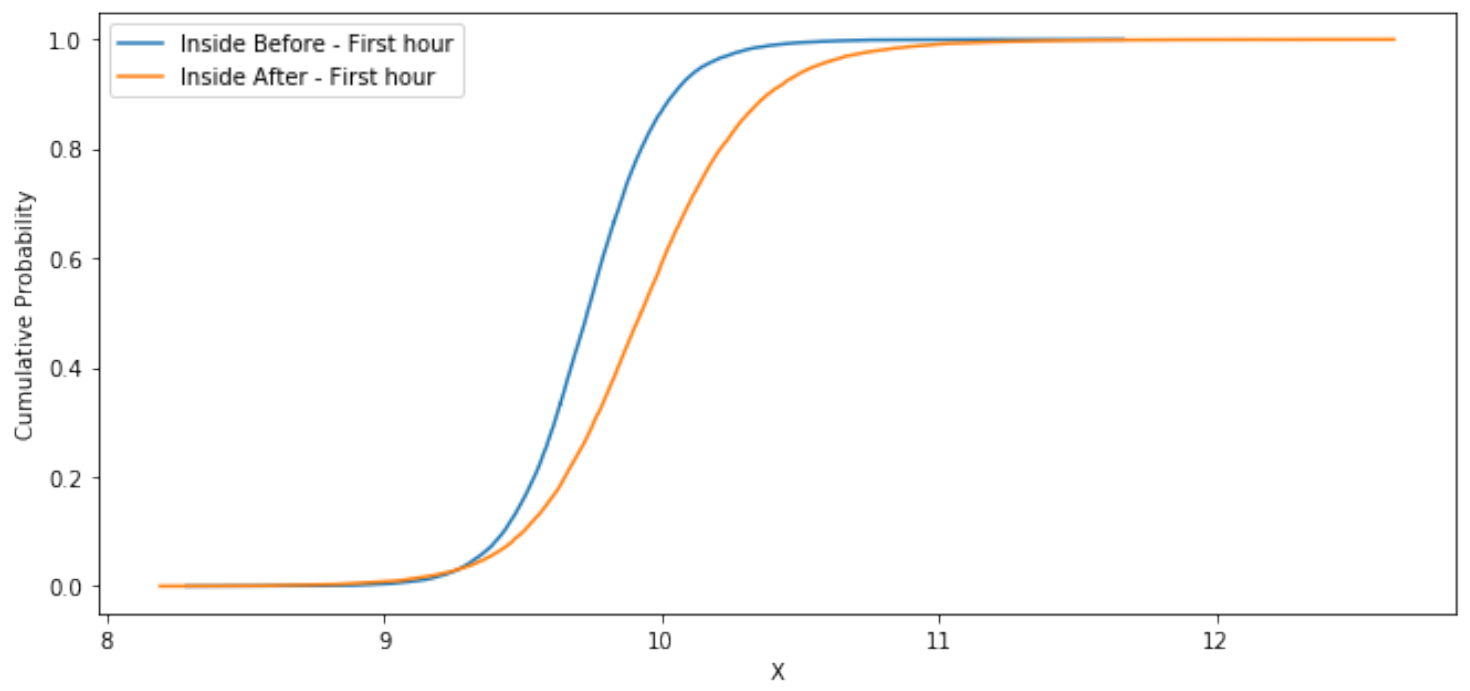

Figure 20. Cumulative Distribution Function for the inside sensor, before and after inserting the RPWs for the first hour.

\subsection{Lessons Learned}

In the end, we conclude that the accelerometer sensor is useful in the early detection of the red palm weevil infestation in palm trees. Our initial results confirm the possibility of finding a clear signature of the infestation using both signal processing and statistical techniques. The results of the inside sensor placement seem to be more robust than those of the outside placement, very likely due to more immunity against external noises. It is recommended to develop a conic metallic material that can be inserted well inside the palm tree and gets attached to an accelerometer and vibration sensor to be able to improve the features of the infestation signals. Moreover, the IoT system that is developed in the context of this project provides a full-stack prototype for the real-time monitoring of palms trees, which, combined with signal processing results of the infestation, contributes uniquely to early detection of infestations.

\section{Conclusions}

In this paper, we proposed SmartPalm, an integrated Internet-of-Things system for the monitoring of palm trees' farms, and the early detection of the red palm weevil. We presented the system architecture, and we implemented it using the IoT platform of Elm company. SmartPalm provides the farmers with an effective means to monitor and manage their palm tree farms. Moreover, using advanced signal processing and probabilistic methods techniques, the system allows detecting with accuracy the infestation of the palm tree with the red palm weevil. The system was deployed on a real-palm tree, and results were validated.

There are several challenges in what concerns the research on the red palm weevil. The most critical challenge is the finding of a proper sensor that can identify with accuracy the activity of the red palm weevil. Although there are a few solutions in the market, there is still a need to investigate more robust and reliable sensing technologies. Furthermore, the filtering of the signal and the extraction of useful data from the noise is another challenge. One attractive research area is to apply machine learning and deep learning models for the analysis of the activity signal and its classification. However, these approaches require the collection of a considerable amount of data, which is quite challenging.

We are currently working on extending the SmartPalm system in several ways for the sake of its commercialization. First, we are making further investigations on developing additional sensors for the early detection of red palm weevil based on acoustic signals and chemical signals. The chemical sensor is aimed to detect the pheromone odor of the red palm weevil. Furthermore, we aim at investigating the use of the multi-spectral camera with Internet-connected drones (e.g., [34-36]) for 
the health monitoring of the palm trees, and their counting and geolocation [37]. We are also looking at securing the communication at the sensor level by using encryption and authentication of the sensor data [38] to avoid security threats and attacks.

Author Contributions: Conceptualization, A.K. and A.A. (Abdulrahman Aldawood); Data curation, A.K., B.S., A.H., M.A. (Mohanned Ahmed), A.S. and H.A.; Formal analysis, A.K., A.H. and A.A. (Adel Ammar); Funding acquisition, A.K., A.A. (Abdulrahman Aldawood) and M.A. (Mohamed Alkanhal); Investigation, A.K., A.A. (Abdulrahman Aldawood), B.S., A.H., M.A. (Mohanned Ahmed), A.S. and H.A.; Methodology, A.K. and A.A. (Abdulrahman Aldawood); Project administration, A.K., A.A. (Abdulrahman Aldawood) and M.A. (Mohamed Alkanhal); Resources, A.K. and A.A. (Abdulrahman Aldawood); Supervision, A.K. and A.A. (Abdulrahman Aldawood); Validation, A.K. and A.A. (Abdulrahman Aldawood); Visualization, A.K. and A.A. (Adel Ammar); Writing-original draft, A.K., A.A. (Abdulrahman Aldawood), B.S., A.H., M.A. (Mohanned Ahmed), A.S. and H.A.; Writing-review \& editing, A.K., A.A. (Abdulrahman Aldawood) and A.A. (Adel Ammar). All authors have read and agreed to the published version of the manuscript.

Funding: This work is supported by Elm Company, and by the Robotics and Internet-of-Things Lab of Prince Sultan University.

Acknowledgments: This work is supported by Elm Company, within the Robotics and Internet-of-Things Lab; and by the Prince Sultan University. We would like also to thank Mona Alduailej, Assistant in Computational Statistics in Princess Norah University, for her insights in the statistical analysis section.

Conflicts of Interest: The authors declare no conflict of interest. The funders had no role in the design of the study; in the collection, analyses, or interpretation of data; in the writing of the manuscript, or in the decision to publish the results.

\section{References}

1. Red Palm Weevil, Food and Agriculture Organization of the United Nations (FAO). Available online: http:/ / www.fao.org/food-chain-crisis/how-we-work/plant-protection/red-palm-weevil/en/ (accessed on 28 February 2020).

2. Mukhtar, M.; Rasool, K.G.; Parrella, M.P.; Sheikh, Q.I.; Pain, A.; Lopez-Llorca, L.V.; Aldryhim, Y.N.; Mankin, R.; Aldawood, A.S. New initiatives for management of red palm weevil threats to historical Arabian date palms. Fla. Entomol. 2011, 94, 733-736. [CrossRef]

3. El-Sabea, A.M.; Faleiro, J.; Abo-El-Saad, M.M. The threat of red palm weevil Rhynchophorus ferrugineus to date plantations of the Gulf region in the Middle-East: An economic perspective. Outlooks Pest Manag. 2009, 20, 131-134. [CrossRef]

4. Abraham, V.; Shuaibi, M.A.; Faleiro, J.; Abozuhairah, R.; Vidyasagar, P.S. An integrated management approach for red palm weevil Rhynchophorus ferrugineus Oliv. a key pest of date palm in the Middle East. Sultan Qaboos Univ. J. Sci. Res. Agric. Sci. 1998, 3, 77-84. [CrossRef]

5. Rajamanickam, K.; Christopher, A.; Kennedy, J. Certain components of integrated management for red palm weevil, Rhynchophorus ferrugineus F. (Curculionidae: Coleoptera) on coconut [in South India]. In Mededelingen; Faculteit Landbouwkundige en Toegepaste Biologische; Wetenschappen Universiteit Gent: Gent, Belgium, 1995.

6. Faghih, A.A.; others. The biology of red palm weevil, Rhynchophorus ferrugineus Oliv. (Coleoptera, Curculionidae) in Saravan region (Sistan \& Balouchistan province, Iran). Appl. Entomol. Phytopathol. 1996, 63, 16-18.

7. Muangprathub, J.; Boonnam, N.; Kajornkasirat, S.; Lekbangpong, N.; Wanichsombat, A.; Nillaor, P. IoT and agriculture data analysis for smart farm. Comput. Electron. Agric. 2019, 156, 467-474. [CrossRef]

8. Huuskonen, J.; Oksanen, T. Soil sampling with drones and augmented reality in precision agriculture. Comput. Electron. Agric. 2018, 154, 25-35. [CrossRef]

9. Gao, X.; Li, J.; Fan, L.; Zhou, Q.; Yin, K.; Wang, J.; Song, C.; Huang, L.; Wang, Z. Review of Wheeled Mobile Robots' Navigation Problems and Application Prospects in Agriculture. IEEE Access 2018, 6, 49248-49268. [CrossRef]

10. Kamilaris, A.; Prenafeta-Boldú, F.X. Deep learning in agriculture: A survey. Comput. Electron. Agric. 2018, 147, 70-90. [CrossRef]

11. Hetzroni, A.; Soroker, V.; Cohen, Y. Toward practical acoustic red palm weevil detection. Comput. Electron. Agric. 2016, 124, 100-106. [CrossRef] 
12. Salem, M.S.; Belal, M.H.; Nour, M.E.; Sayed, E.A. Detection of a chemical marker from ovipositing females in Rhynchophorus ferrugineus (Coleoptera: Curculiondae). Adv. Environ. Biol. 2012, 6, 2164-2169.

13. Rach, M.M.; Gomis, H.M.; Granado, O.L.; Malumbres, M.P.; Campoy, A.M.; Martín, J.J.S. On the design of a bioacoustic sensor for the early detection of the red palm weevil. Sensors 2013, 13, 1706-1729. [CrossRef] [PubMed]

14. Hussain, A.; Rizwan-ul Haq, M.; Al-Jabr, A.M.; Al-Ayied, H.Y. Managing invasive populations of red palm weevil: A worldwide perspective. J. Food Agric. Env. 2013, 11, 456-463.

15. Potamitis, I.; Ganchev, T.; Kontodimas, D. On automatic bioacoustic detection of pests: The cases of Rhynchophorus ferrugineus and Sitophilus oryzae. J. Econ. Entomol. 2009, 102, 1681-1690. [CrossRef]

16. Mao, Y.; Ashry, I.; Ng, T.K.; Ooi, B.S. Towards Early Detection of Red Palm Weevil using Optical Fiber Distributed Acoustic Sensor. In Proceedings of the 2019 Optical Fiber Communications Conference and Exhibition (OFC), San Diego, CA, USA, 3-7 March 2019; pp. 1-3.

17. Ashry, I.; Mao, Y.; Al-Fehaid, Y.; Al-Shawaf, A.; Al-Bagshi, M.; Al-Brahim, S.; Ng, T.K.; Ooi, B.S. Early detection of red palm weevil using distributed optical sensor. Sci. Rep. 2020, 10, 1-8. [CrossRef]

18. Nakash, J.; Osem, Y.; Kehat, M. A suggestion to use dogs for detecting red palm weevil (Rhynchophorus ferrugineus) infestation in date palms in Israel. Phytoparasitica 2000, 28, 153-155. [CrossRef]

19. Faleiro, J.; Kumar, J.A. A rapid decision sampling plan for implementing area-wide management of the red palm weevil, Rhynchophorus ferrugineus, in coconut plantations of India. J. Insect Sci. 2008, 8, 15. [CrossRef] [PubMed]

20. Giovino, A.; Bertolini, E.; Fileccia, V.; Al Hassan, M.; Labra, M.; Martinelli, F. Transcriptome analysis of Phoenix canariensis Chabaud in response to Rhynchophorus ferrugineus Olivier attacks. Front. Plant Sci. 2015, 6, 817. [CrossRef]

21. Farooq, W.; Rasool, K.; Tawfik, W.; Aldawood, A. Application of Laser Induced Breakdown Spectroscopy in Early Detection of Red Palm Weevil: (Rhynchophorus ferrugineus) Infestation in Date Palm. Plasma Sci. Technol. 2015, 17, 948. [CrossRef]

22. Kemsley, E.K.; Tapp, H.S.; Binns, R.; Mackin, R.O.; Peyton, A.J. Feasibility study of NIR diffuse optical tomography on agricultural produce. Postharvest Biol. Technol. 2008, 48, 223-230. [CrossRef]

23. Ahmed, A.; Ibrahim, A.; Hussein, S. Detection of palm tree pests using thermal imaging: A review. In Machine Learning Paradigms: Theory and Application; Springer: Berlin/Heidelberg, Germany, 2019; pp. 253-270.

24. Abdullah, M. Biological control of the red palm weevil, Rhynchophorus ferrugineus (Olivier) (Coleoptera: Curculionidae) by the parasitoid mite, Rhynchopolipus rhynchophori (Ewing) (Acarina: Podapolipidae). J. Egypt. Soc. Parasitol. 2009, 39, 679-686.

25. Tofailli, K. The early detection of red palm weevil: A new method. Acta Hortic. 2010, 882, 441-450. [CrossRef]

26. Soroker, V.; Suma, P.; Pergola, A.l.; Cohen, Y.; Alchanatis, V.; Golomb, O.; Goldshtein, E.; Hetzroni, A.; Galazan, L.; Kontodimas, D. Early detection and monitoring of red palm weevil: Approaches and challenges. In Proceedings of the Colloque méditerranéen sur les Ravageurs des Palmiers, Association Française de Protection des Plantes (AFPP), Nice, France, 16-18 January 2013.

27. Gutiérrez, A.; Ruiz, V.; Moltó, E.; Tapia, G.; del Mar Téllez, M. Development of a bioacoustic sensor for the early detection of Red Palm Weevil (Rhynchophorus ferrugineus Olivier). Crop Prot. 2010, 29, 671-676. [CrossRef]

28. Potamitis, I.; Ganchev, T.; Fakotakis, N. Automatic bioacoustic detection of Rhynchophorus ferrugineus. In Proceedings of the 2008 16th European Signal Processing Conference, Lausanne, Switzerland, 25-29 August 2008; pp. 1-4.

29. Walid Barakat Hussein.; Mohamed Ahmed, H.; Becker, T. Application of the signal processing technology in the detection of Red Palm Weevil. In Proceedings of the 2009 17th European Signal Processing Conference, Glasgow, Scotland, UK, 24-28 August 2009; pp. 1597-1601.

30. Smart Palm Video Demonstration. Available online: https://youtu.be/qnniODMK3xc (accessed on 28 February 2020).

31. Elm Company. 2020. Available online: https:/ / elm.sa/en (accessed on 24 February 2020).

32. Grove-3-Axis Digital Accelerometer $\pm 16 g$ Ultra-Low Power (BMA400). 2019. Available online: http:/ / wiki. seeedstudio.com/Grove-3-Axis_Digital_Accelerometer\%C2\%B116g_Ultra-low_Power-BMA400/ (accessed on 4 July 2019).

33. Grove-Piezo Vibration Sensor. 2019. Available online: http://wiki.seeedstudio.com/Grove-Piezo_ Vibration_Sensor/ (accessed on 4 July 2019). 
34. Koubâa, A.; Qureshi, B.; Sriti, M.F.; Allouch, A.; Javed, Y.; Alajlan, M.; Cheikhrouhou, O.; Khalgui, M.; Tovar, E. Dronemap Planner: A service-oriented cloud-based management system for the Internet-of-Drones. Ad Hoc Netw. 2019, 86, 46-62. [CrossRef]

35. Koubaa, A.; Qureshi, B.; Sriti, M.F.; Javed, Y.; Tovar, E. A service-oriented Cloud-based management system for the Internet-of-Drones. In Proceedings of the 2017 IEEE International Conference on Autonomous Robot Systems and Competitions (ICARSC), Coimbra, Portugal, 26-28 April 2017; pp. 329-335. [CrossRef]

36. Koubaa, A.; Qureshi, B. DroneTrack: Cloud-Based Real-Time Object Tracking Using Unmanned Aerial Vehicles Over the Internet. IEEE Access 2018, 6, 13810-13824. [CrossRef]

37. Ammar, A.; Koubaa, A. Deep-Learning-based Automated Palm Tree Counting and Geolocation in Large Farms from Aerial Geotagged Images. arXiv 2020, arXiv:2005.05269. Available online: https://arxiv.org/ abs / 2005.05269 (accessed on 8 July 2020).

38. Cheikhrouhou, O.; Koubaa, A.; Boujelben, M.; Abid, M. A lightweight user authentication scheme for wireless sensor networks. In Proceedings of the ACS/IEEE International Conference on Computer Systems and Applications-AICCSA 2010, Hammamet, Tunisia, 16-19 May 2010; IEEE: Piscataway, NJ, USA, 2010; pp. 1-7.

(C) 2020 by the authors. Licensee MDPI, Basel, Switzerland. This article is an open access article distributed under the terms and conditions of the Creative Commons Attribution (CC BY) license (http://creativecommons.org/licenses/by/4.0/). 